\title{
EFFECTS OF REDUCING THE EXTRACELLULAR CALCIUM CONCENTRATION ON THE RESTING POTENTIAL OF FROG'S SKELETAL MUSCLE FIBERS*
}

\author{
G. B. Frank and F. Inoue \\ Department of Pharmacology, The University of Alberta, Edmonton, Canada
}

\begin{abstract}
Summary Exposing one end of a frog's toe muscle (ex. dig. long. IV) in a sucrose gap apparatus to a $\mathrm{Ca}^{++}$-free Ringer solution resulted in a depolarization of about $15 \mathrm{mV}$ in about $20-25 \mathrm{~min}$ (or $40-45 \mathrm{~min}$ in a choline Ringer solution) with very little further depolarization with continued exposure $\left(1 \mathrm{hr}\right.$ or more). As little as $0.05 \mathrm{mM} \mathrm{Ca}^{++}$was sufficient to prevent or greatly reduce the depolarization. Means and frequency histograms of membrane potentials recorded with intracellular microelectrodes were plotted for fixed time periods of exposure to $0-\mathrm{Ca}^{++}$. The mean depolarizations were between 12 and $35 \mathrm{mV}$ when tested $15 \mathrm{~min}$ after exposure to $0-\mathrm{Ca}^{++}$but were only about $10-15 \mathrm{mV}$ when first tested after a 1-hr exposure; the maximum fall observed was about $55 \mathrm{mV}$ after $90 \mathrm{~min}$ and 4 periods of sampling. The most consistent change produced by $0-\mathrm{Ca}^{++}$was a flattening and broadening of the frequency histogram. These results suggest that the large falls $(>20 \mathrm{mV})$ in frog' skeletal muscle membrane potentials in $0-\mathrm{Ca}^{++}$solutions seen here and often reported by other workers are an artifact produced by the intracellular microelectrodes on the cell membranes made fragile by the reduction in membrane $\mathrm{Ca}^{++}$.
\end{abstract}

In a detailed study of the effects of changes in extracellular calcium concentrations on the resting and action potentials of toad skeletal muscle fibers using intracellular microelectrodes, IsHIKO and SATO (1957) observed in a few experiments that the resting potentials were reduced and the fibers became inexcitable after about $1 \mathrm{hr}$ in a calcium-free solution. However, in other "later" experiments excitability remained and presumably the resting potential was not greatly reduced under the same conditions. Subsequently, many other investigators have reported large reductions $(>20 \mathrm{mV})$ in the intracellularly recorded resting poten-

Received for publication January 29, 1973

* This work was supported by a grant from the Medical Research Council of Canada.

井上交武 
tials of amphibian muscle fibers kept in calcium-free Ringer solution (AвOOD et al., 1963; Edman and Grieve, 1962, 1963a, 1963b, 1964; JeNDEN and Reger, 1963; KoKETSU and NoDA, 1962; LÜTTGAU, 1963) or calcium-free choline-Ringer solution (CuRTIS, 1963).

In contrast we were unable to detect any change in the resting potentials in frog's toe muscle fibers kept in a calcium-free choline-Ringer solution for $5 \mathrm{~min}$ (FrANK, 1964). Milligan (1965) reported only a $17-\mathrm{mV}$ fall in mean resting potential after a 20-min exposure to a calcium-free tris-Ringer solution and BRECHT et al. (1963) found only a 10-mV fall after keeping a frog's sartorius muscle in a calcium-free Ringer solution for $255 \mathrm{~min}$ or a $15-\mathrm{mV}$ fall after $160 \mathrm{~min}$ in a bath with a continuous perfusion of the calcium-free solution.

Moreover, the large fall in resting potential $(>20 \mathrm{mV})$ in the absence of extracellular calcium ions seems to occur only in amphibian and possibly mammalian (EDMAN and GRIEVE, 1963b) skeletal muscle. Removal of extracellular calcium ions in vitro does not alter the membrane resting potentials of striated muscles from crayfish (ZACHAROvÁ and ZACHAR, 1967) or lobster (GAINER, 1968) and causes only a small fall in resting potential (usually about $4 \mathrm{mV}$ ) in squid axons (FRANKENHAEUSER and HoDgKIN, 1957) or in myelinated nerve fibers (STÄMPFli and NiShie, 1956; FrankenhaeuSER, 1957).

It was our initial intention to study in detail the effects of divalent cations which have been reported to antagonize the large fall in resting potential produced by calcium removal (Jenden and Reger, 1963; Fischman and Swan, 1967). In order to facilitate the simultaneous recording of the resting potentials of all the fibers in a frog's toe muscle, a sucrose gap apparatus was employed. To our surprise we were never able to record large reductions $(>20 \mathrm{mV})$ in the mean resting potential but only a slowly developing depolarization of about $20 \mathrm{mV}$ or less reaching a maximum in about $20-25 \mathrm{~min}$ in Ringer and $40-45 \mathrm{~min}$ in cholineRinger solution. Further studies of the conditions required for producing the large fall in mean resting potential with intracellular microelectrodes have led us to conclude that the latter is an artifact produced by the insertion of the microelectrode when the muscle is exposed to a calcium-free solution.

A preliminary account of this work has already appeared (FRANK and INOUE, 1972).

\section{METHODS}

Preparation. All experiments were conducted using the extensor longus digiti IV muscle (toe muscle) of the frog Rana pipiens. For details concerning the isolation procedure, the size and other features of this muscle see FrANK (1960).

Sucrose gap. Since its initial introduction by STÄMPFLI (1954), the sucrose gap apparatus frequently has been modified in accordance with the requirements necessitated by various types of experiments. In the present study in order to 

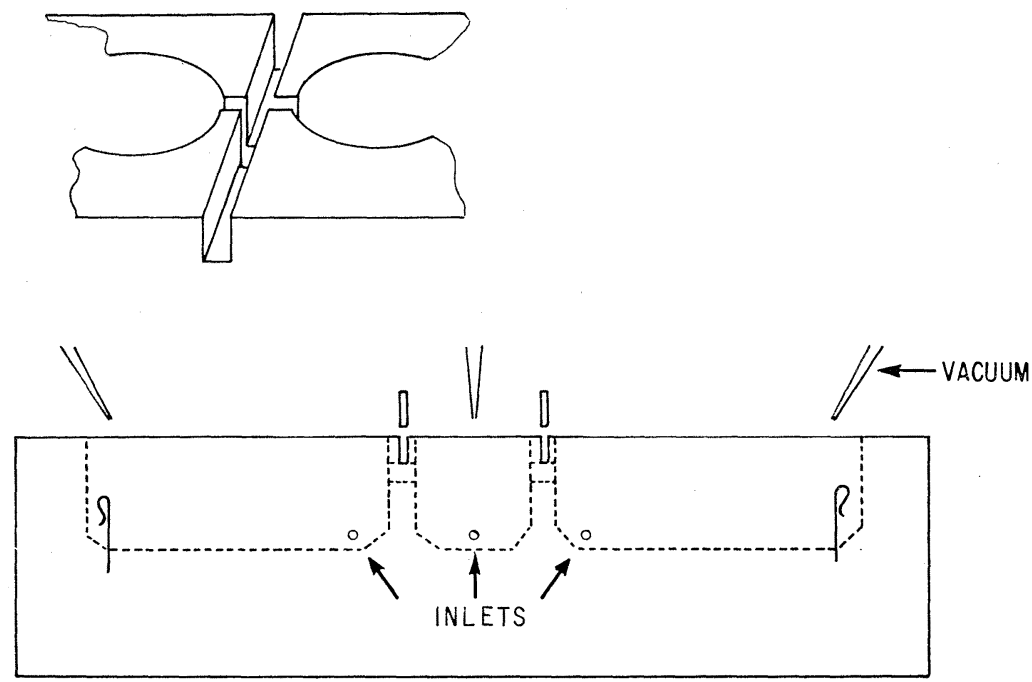

Fig. 1. Diagrammatic illustration of the three-chambered bath used for the sucrose gap experiments. The channel connecting the chambers to each other is shown in insert at upper left. The width of the grooves was $0.5 \mathrm{~mm}$ and the length of gaps between the baths was $1 \mathrm{~mm}$. See text for further details.

measure the relatively small, slowly developing membrane potential changes produced by exposing a frog's toe muscle to a calcium-free solution, an extremely stable sucrose gap arrangement was required. For example, in a preliminary series of experiments performed about 2 years prior to the present study, we were forced to conclude that any potential changes produced by exposure to a calciumfree solution were less than the inherent drift of our system which was about 20-25 mV/hr. In the present series of experiments the three chambers of the bath (Fig. 1) were perfused with the control solutions for 1 to $2 \mathrm{hr}$ with the muscle in place before testing commenced. Although there was considerable drift when recording began, in successful experiments by the time test solutions wereintroduced there was a maximum phasic drift of 1 to $2 \mathrm{mV}$ and a maximum D.C. drift of $<1 \mathrm{mV} / \mathrm{hr}$.

The three-chamber bath designed for this study (Fig. 1) was cut out of a lucite block. All surfaces of the two channels connecting the chambers to each other were first covered with a thin layer of silicone stopcock grease (Dow Chemical Co.) and then the channels were filled with petoleum jelly. A path wide enough to accommodate the muscle was cut in the petroleum jelly and the muscle placed in the bath attached by silk threads tied to the end tendons and held by the fine pinch clamps at the ends of the two side chambers. Next the lengths of muscle in the channels were blotted with pieces of filter paper, covered with petroleum jelly and the small lucite blocks inserted. Finally the jelly on each side of each channel was smoothed with a fine spatula and the jelly inspected for air bubbles 
or fine threads which occasionally bridged the channels. This whole procedure was carried out under a dissecting microscope. With the small blocks in place there was a small square hole $(0.5 \mathrm{~mm}$ on each side) connecting the chambers. This hole was filled with the muscle and the jelly when the bath was in use.

The chambers were perfused by a gravity flow system. The solutions entered by means of the inlets at the bottom of each chamber and were removed by suction at the top. A separate system was required for each chamber to prevent electrical short-circuiting. The side chambers contained about $1.2 \mathrm{ml}$ and the central chamber about $0.8 \mathrm{ml}$. Each chamber was continuously perfused with fresh solution at a rate of about $12 \mathrm{ml} / \mathrm{min}$. In order to reduce the extracellular calcium concentration rapidly, the test chamber was drained with a syringe immediately before the start of the perfusion with a calcium-free or a reduced calcium solution. Although the test chamber was usually drained prior to perfusion with an elevated potassium solution, this preliminary draining did not appear to accelerate or otherwise modify the subsequent depolarization.

For electrical recording, each of the side chambers was connected with an agar-bridge to a pool containing $3 \mathrm{M} \mathrm{KCl}$. The agar was made up in calciumfree Ringer or calcium-free choline-Ringer solution. The electrodes connecting the $3-\mathrm{M} \mathrm{KCl}$ pools to the amplifier were constructed from 1-ml plastic syringes filled with $3 \mathrm{M} \mathrm{KCl}$ and containing a chlorided silver wire having a surface area of about $2.5 \mathrm{~cm}^{2}$. The $3 \mathrm{M} \mathrm{KCl}$ was allowed to equilibrate with solid silver chloride salt for several days prior to use. A Radiometer $\mathrm{pH}$ meter (Model 27b) was used as the amplifier and records were made with a Bausch and Lomb potentiometric recorder (Model No. VOM 5).

The isotonic sucrose (246 mM) which perfused the central chamber had a specific resistance of between 2 and 3 megohm-cm and was obtained in the following manner. The sucrose solution prepared with deionized water was passed through a mixed bed ion exchange resin. The column was prepared by mixing 1 part by volume of amberlite IRC-50 resin with 1.5 parts by volume of amberlite IRA-410 resin (Rohm \& Haas Co., Philadelphia). By reducing the flow rate through the column resistances as high as 6 megohm-cm can be obtained.

Microelectrodes. The techniques employed for recording membrane resting potentials with intracellular microelectrodes were in no way unusual and the details can be found elsewhere (INOUE and Frank, 1962). The procedure adopted was designed to reduce experimenter bias and artifacts to a minimum. The membrane potentials were recorded in groups of 10 to 20 at a single point along the length of the muscle. Since these were very small muscles this necessitated recording potentials from fibers 1 or 2 layers beneath the surface as well as from surface fibers. All the observed potentials which could possibly be membrane potentials were recorded. Each recording point for a group of potential measurements was separated by a distance of at least $2 \mathrm{~mm}$ along the length of the muscle.

Solutions. The Ringer solution had the following composition (mM): $\mathrm{NaCl}$, 
111.8; KCl, 2.47; $\mathrm{CaCl}_{2}, 1.08 ; \mathrm{NaHCO}_{3}, 2.38 ; \mathrm{NaH}_{2} \mathrm{PO}_{4}, 0.087$; glucose, 11.1. The choline-Ringer solution had the same composition with the exception that choline chloride was substituted for $\mathrm{NaCl}$. The Ringer solution but not the choline-Ringer solution contained $10^{-4} \mathrm{~g} / \mathrm{ml}$ of $d$-tubocurarine chloride. The solutions with reduced calcium concentrations were made by omitting or reducing the $\mathrm{CaCl}_{2}$ concentration without any other adjustment. The isotonic $\mathrm{KCl}$ solution contained $123 \mathrm{~mm} \mathrm{KCl}$.

All experiments were conducted at room temperature (from $23^{\circ}$ to $27^{\circ} \mathrm{C}$ ).

\section{RESULTS}

a) Membrane potentials recorded with the sucrose gap: Calcium-free solutions

The results obtained in an experiment with Ringer solution are presented in Fig. 2. When one of the outer chambers of the sucrose-gap apparatus was perfused with a calcium-free solution there was a slowly developing depolarization which levelled off after about 20 to $25 \mathrm{~min}$ of perfusion (Fig. 2B). Continuing the perfusion for an additional 30 to $60 \mathrm{~min}$ resulted in an additional 1- or 2- $\mathrm{mV}$ depolarization at most. The slow development of the depolarization was not an artifact due to mixing because just before the start of the perfusion the chamber

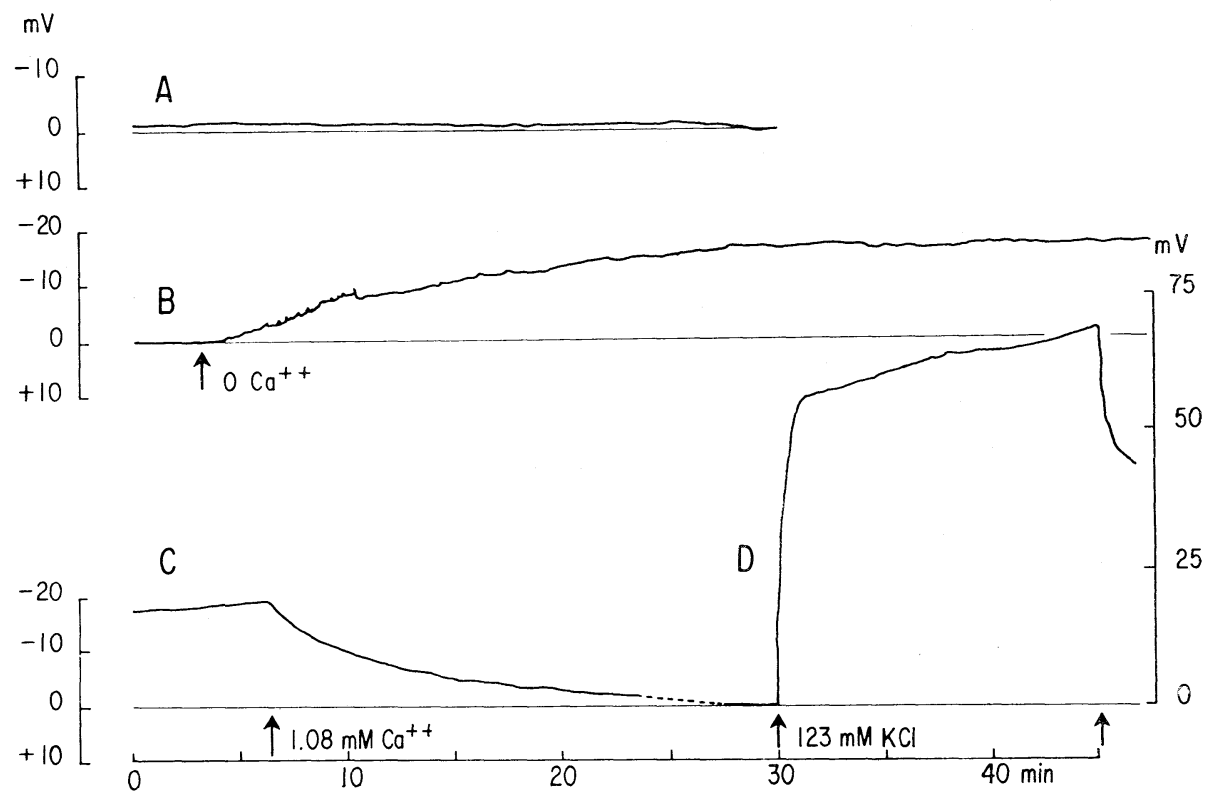

Fig. 2. Depolarization produced by removing calcium ions from the Ringer solution perfusing one of the chambers of the sucrose-gap apparatus. Tracings from actual record. A, B, and $\mathrm{C}$, continuous record with exception of dashed portion in $\mathrm{C}$ which represents a break in the record of about $50 \mathrm{~min}$. 
was completely drained and then filled with the calcium-free solution. In addition each of the side-chambers of the bath which contained about $1.2 \mathrm{ml}$ was perfused with solution at a rate of about $12 \mathrm{ml} / \mathrm{min}$. The initial rate of recovery of membrane potential upon return of calcium to the perfusion (Fig. 2C) tended to be slightly faster than the rate of depolarization in calcium-free solutions but full recovery of the membrane potential took 2 to 3 times as long as the time required to reach the depolarization plateau.

Although similar in most respects to the results obtained with calcium-free Ringer solution, the experiment illustrated in Fig. 2 was atypical in that the depolarization produced with the calcium-free solution (19 $\mathrm{mV}$ after $50 \mathrm{~min})$ was the largest we recorded in this series of experiments. These results are presented in Table 1.

Table 1. Depolarizations produced by reducing the extracellular calcium concentration to 0 recorded using the sucrose-gap apparatus. The potentials listed were obtained after a 50-60-min exposure to a $0-\mathrm{Ca}^{++}$solution or after a $10-\mathrm{min}$ exposure to isotonic $\mathrm{KCl}(123 \mathrm{~mm})$.

\begin{tabular}{cccc}
\hline Exp. & $\mathrm{Na}^{+}$-Ringer & Choline-Ringer & Isotonic $\mathrm{KCl}$ \\
\hline & $(\mathrm{mV})$ & $(\mathrm{mV})$ & $(\mathrm{mV})$ \\
921 & 14 & & 50 \\
923 & 19 & & 67 \\
105 & 15 & & 63 \\
204 & 12 & & 58 \\
507 & 15 & & 73 \\
525 & 16 & 16 & 78 \\
924 & & 12 & 81 \\
927 & & 16 & 73 \\
930 & & 13 & 74 \\
1005 & & & 54 \\
\hline
\end{tabular}

The recordings made during an experiment using a choline-Ringer solution are illustrated in Fig. 3. The only noticeable difference between the results obtained with using calcium-free Ringer or calcium-free choline-Ringer solution was that in the latter the depolarization developed more slowly and only reached a plateau after about 40 to $45 \mathrm{~min}$ of perfusion with the calcium-free solution (Fig. 3B, C). The results obtained in several experiments of this type are listed in Table 1.

Only experiments in which the depolarization produced at the end of the experiment by isotonic $\mathrm{KCl}$ was $50 \mathrm{mV}$ or more are listed in Tables 1 and 2 (below). Since the control resting potential values recorded with intracellular microelectrodes (Table 3) averaged about $85 \mathrm{mV}$, the short-circuiting factors were between 0.85 and 0.95 for the experiments with isotonic $\mathrm{KCl}$-produced potentials greater than $70 \mathrm{mV}$. From these experiments it was estimated that exposure to a calciumfree solution produced approximately a $15-\mathrm{mV}$ depolarization of the muscle 

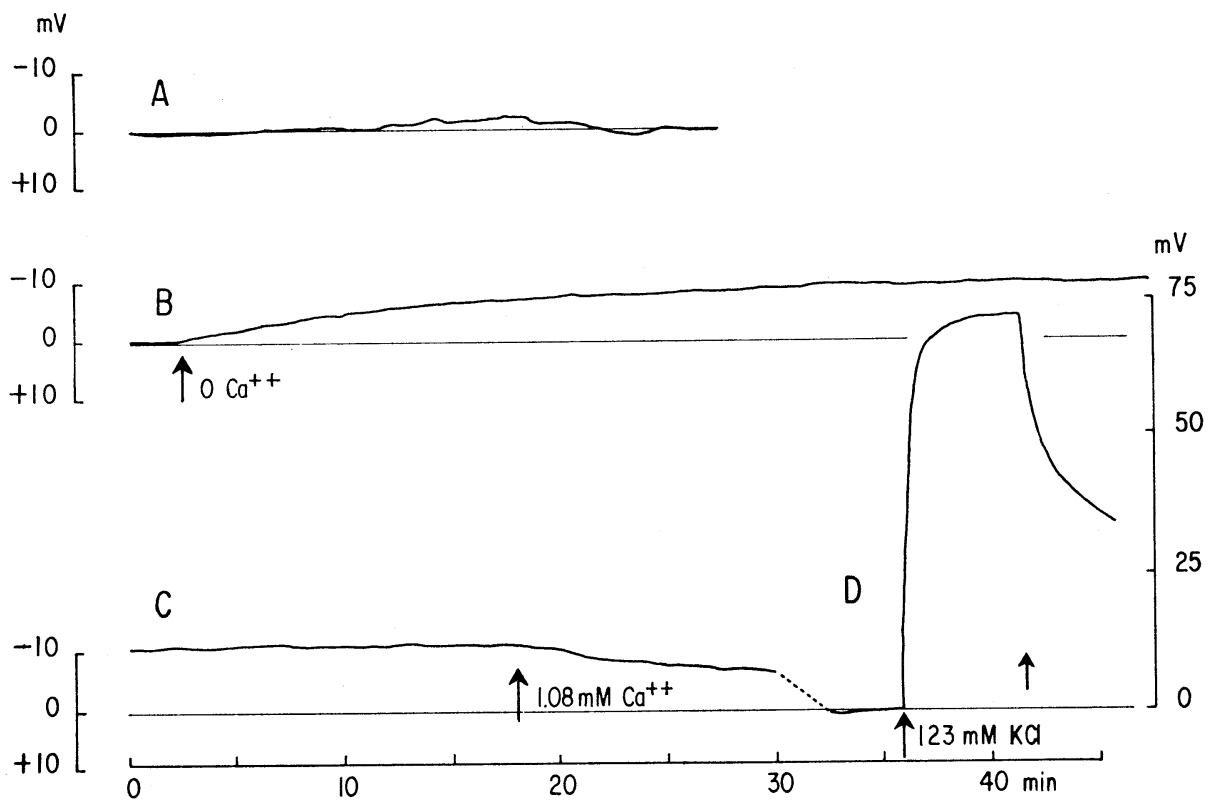

Fig. 3. Depolarization produced by removing calcium ions from the choline-Ringer solution perfusing one of the chambers of the sucrose-gap apparatus. Tracings from actual record. $\mathrm{A}, \mathrm{B}$, and $\mathrm{C}$, continuous record with exception of dashed portion in $\mathrm{C}$ which represents a break in the record of about $50 \mathrm{~min}$.

Table 2. Depolarizations produced by reducing the extracellular calcium concentration recorded using the sucrose gap apparatus. The potentials listed were obtained after a 50-60-min exposure to solutions with a reduced calcium concentration or after a 10-min exposure to isotonic $\mathrm{KCl}(123 \mathrm{~mm})$.

\begin{tabular}{|c|c|c|c|c|}
\hline \multirow{2}{*}{ Exp. } & \multicolumn{3}{|c|}{$\mathrm{Ca}^{++}$concentrations } & \multirow{2}{*}{$\begin{array}{c}\text { Isotonic } \mathrm{KCl} \\
(\mathrm{mV})\end{array}$} \\
\hline & $\underset{(\mathrm{mV})}{0.11 \mathrm{mM}}$ & $\begin{array}{c}0.05 \mathrm{mM} \\
(\mathrm{mV})\end{array}$ & $\underset{(\mathrm{mV})}{0.01 \mathrm{mM}}$ & \\
\hline \multirow{2}{*}{ a) $\mathrm{Na}^{+}$-Ringer } & & & & \\
\hline & & 0 & & 79 \\
\hline $713^{* *}$ & 5 & 2 & & 77 \\
\hline 714 & 5 & 0 & 16 & $\begin{array}{l}73 \\
57\end{array}$ \\
\hline 808 & & & 9 & 56 \\
\hline \multicolumn{5}{|l|}{ b) Choline Ringer } \\
\hline $\begin{array}{l}815 \\
817\end{array}$ & 2 & & 12 & 86 \\
\hline 816 & & & 7 & 81 \\
\hline 818 & & & 13 & 81 \\
\hline 925 & & 5 & & 83 \\
\hline 1005 & 0 & & & 54 \\
\hline 1006 & & & 17 & 76 \\
\hline $1007 * *$ & & 1 & 13 & 76 \\
\hline
\end{tabular}

* Tests on two muscles from the same frog

** Two tests on a single muscle 


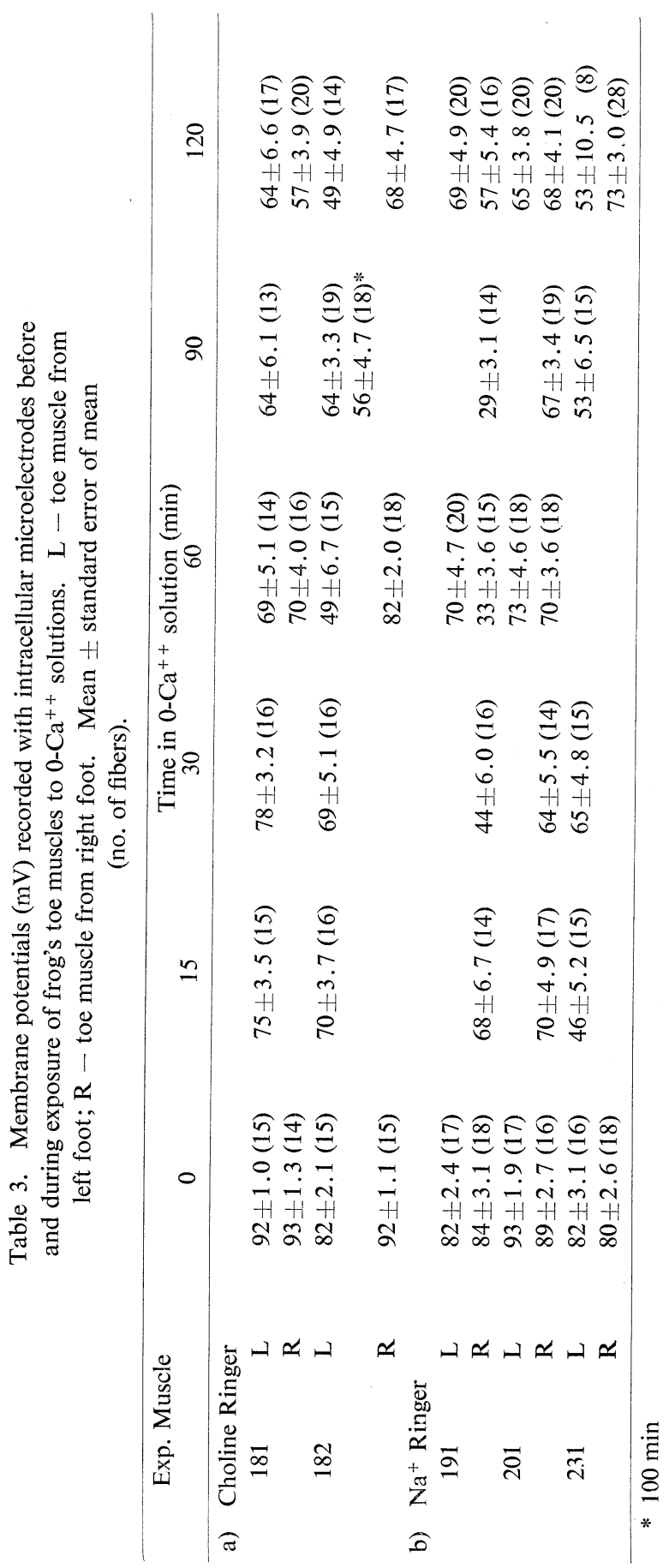


fibers. A comparable average depolarization was recorded with intracellular microelectrodes when they were inserted for the first time after a 1-hr exposure of the muscles to calcium-free solutions (see below-Table 3).

The depolarizations produced by exposure to calcium-free solutions tended to be a bit smaller in the experiments with control isotonic $\mathrm{KCl}$-produced depolarizations $<70 \mathrm{mV}$. However they were not as small as one would expect from the calculated short-circuiting factors; e.g. for a control depolarization of $50 \mathrm{mV}$ the short-circuiting factor would be 0.58 and the depolarization produced by the calcium-free solution should be about $9 \mathrm{mV}$. One can only assume that the shortcircuiting factor was increasing during the course of the experiments and that the response to isotonic $\mathrm{KCl}$ gives only an estimate of the maximum short-circuiting factor at the end of the experiment. On the other hand, in several experiments (not otherwise included in this report) with control depolarizations $<50 \mathrm{mV}$, the depolarizations produced by low $\mathrm{Ca}^{++}$solutions were greatly reduced or eliminated.

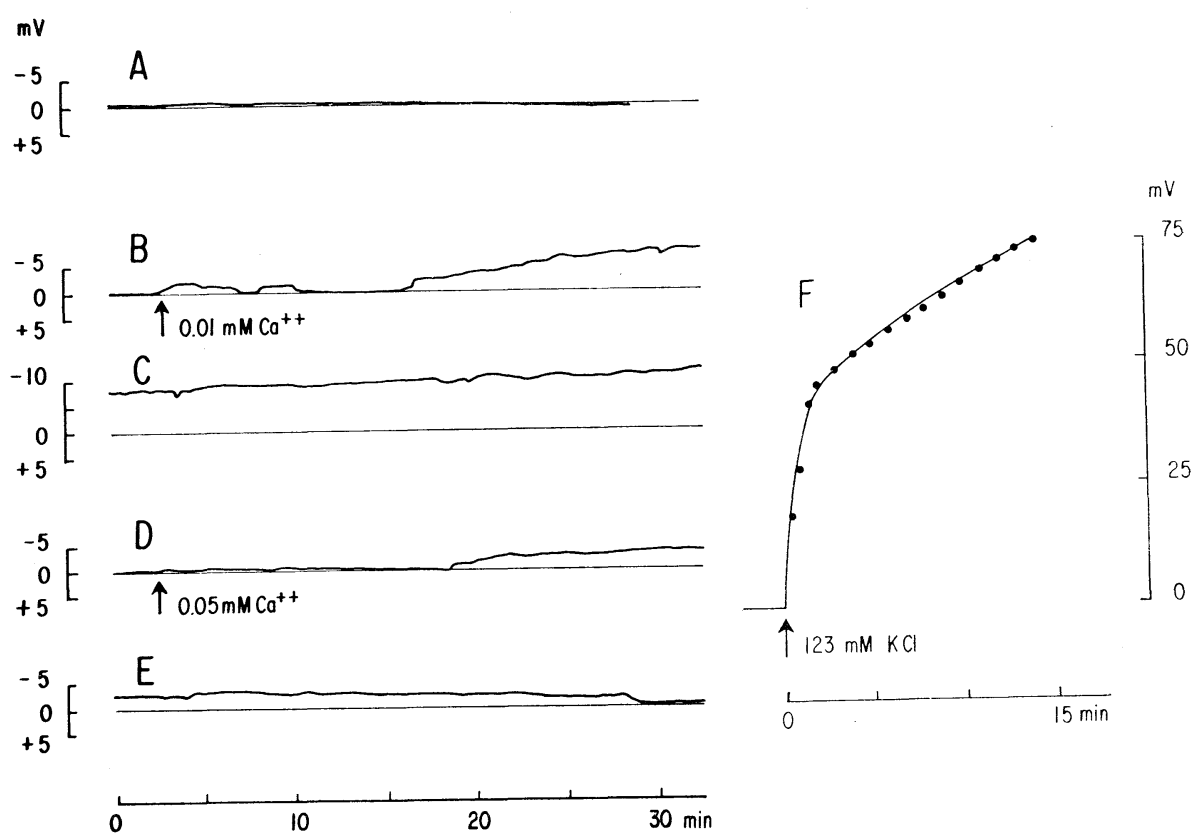

Fig. 4. Depolarizations produced by reducing the calcium ion concentration in the cholineRinger solution perfusing one of the chambers of the sucrose-gap apparatus. A to E, tracings from actual record; $F$, plot of points obtained from a recording made at a faster chart speed. Records from an experiment with a single toe muscle. A, B, and C, continuous record. At end of C, calcium $(1.08 \mathrm{~mm}$ ) added to perfusion fluid. $\mathrm{D}$ and $\mathrm{E}$, continuous record starting about $90 \mathrm{~min}$ after the end of C. At end of E, calcium $(1.08 \mathrm{~mm})$ added to perfusion fluid. $\mathrm{F}$, record starting about $60 \mathrm{~min}$ after end of $\mathrm{E}$. 


\section{b) Sucrose gap: Reduced calcium solutions}

In a few experiments the effects of a partial reduction in the calcium concentration on the membrane potential were determined. In the experiment illustrated in Fig. 4 a calcium concentration of $0.01 \mathrm{~mm}$ was insufficient to prevent the depolarization caused by reduction of extracellular calcium (Fig. 4B, C). However, only a small depolarization was obtained when a solution containing $0.05 \mathrm{~mm}$ calcium was used (Fig. 4D, E). The results obtained in experiments of this type are presented in Table 2. The impression gained was that $0.1 \mathrm{~mm}$ calcium was sufficient to prevent any depolarization, $0.05 \mathrm{~mm}$ calcium was sufficient to greatly reduce or prevent the depolarization, and that with $0.01 \mathrm{~mm}$ calcium the depolarization was about the same as with a calcium-free solution.

c) Intracellular microelectrodes and calcium-free solutions

Since we never observed, using the sucrose-gap apparatus, large depolariza-
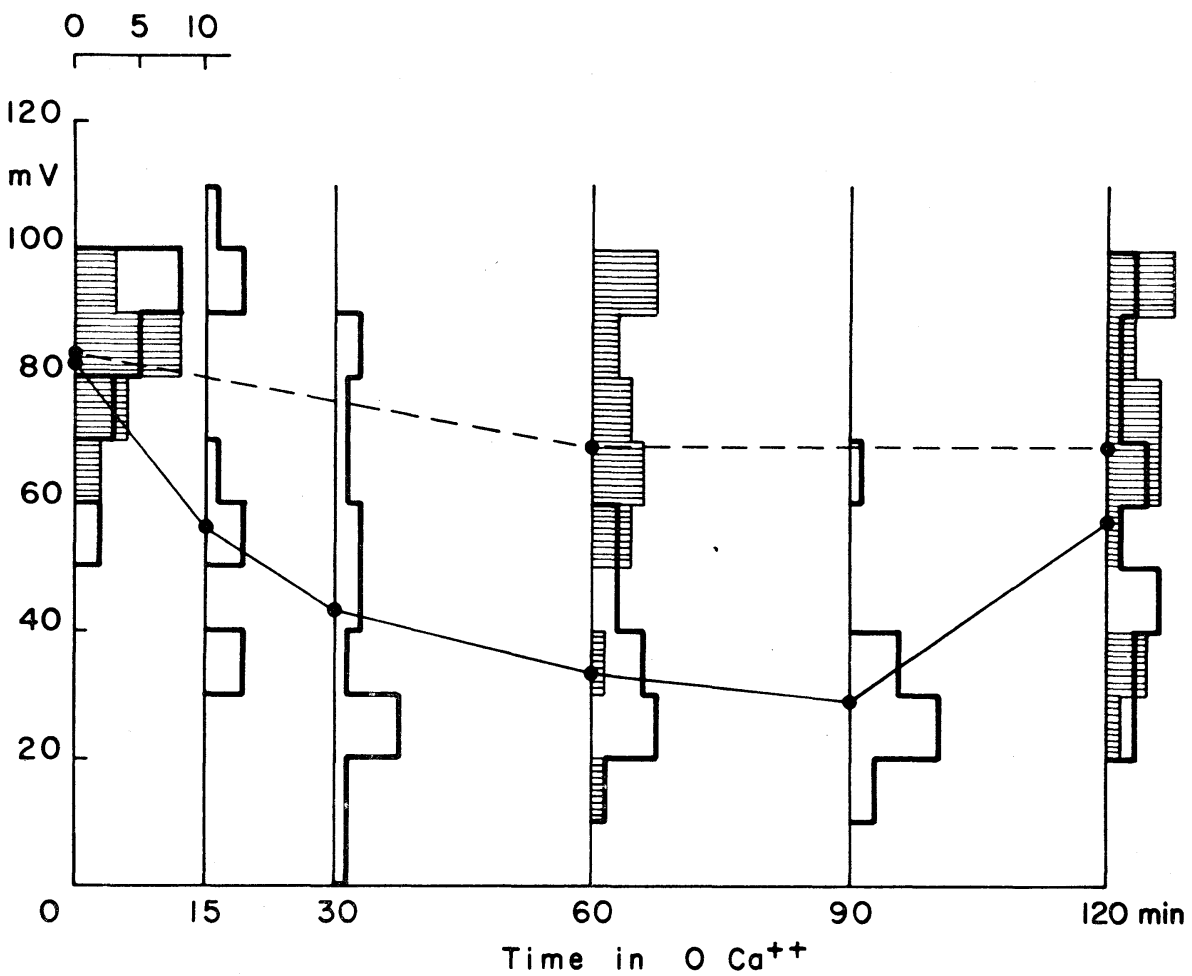

Fig. 5. Resting potentials of fibers in frog's toe muscles kept in a calcium-free Ringer solution. Calibration for histograms in upper left of graph, number of fibers with resting potentials in each $5 \mathrm{mV}$ range. Shaded histogram and dashed line potentials recorded from fibers of one toe muscle; open histogram and solid line potentials recorded from fibers of the other toe muscle from the same frog. Points are means for each group of potentials. 
tions $(>20 \mathrm{mV})$ upon removal of extracellular calcium, experiments were conducted with intracellular microelectrodes. Our aim was to see if we could measure large depolarizations in toe muscles bathed in calcium-free solutions using microelectrodes as reported by others and if possible to determine the conditions favouring the production of large depolarizations in calcium-free solutions. After a few preliminary experiments, the following procedure was adopted. Both toe muscles from a single frog were removed and mounted in separate baths to facilitate recording. After control measurements were made the muscles were placed in a calcium-free solution. In one muscle of the pair, resting potentials were recorded at the end of $60 \mathrm{~min}$ and $120 \mathrm{~min}$ and in the other, measurements were made at the end of 15, 30, 60, 90, and 120min (Fig. 5, Table 3). Four such experiments were conducted; two with Ringer and two with choline-Ringer solution. In another experiment with Ringer solution, a slightly different time sequence was employed (Fig. 6, Table 3).

In Figs. 5 and 6 both the means and the frequency histograms for each group of resting potentials are plotted. Although as expected the mean resting potential

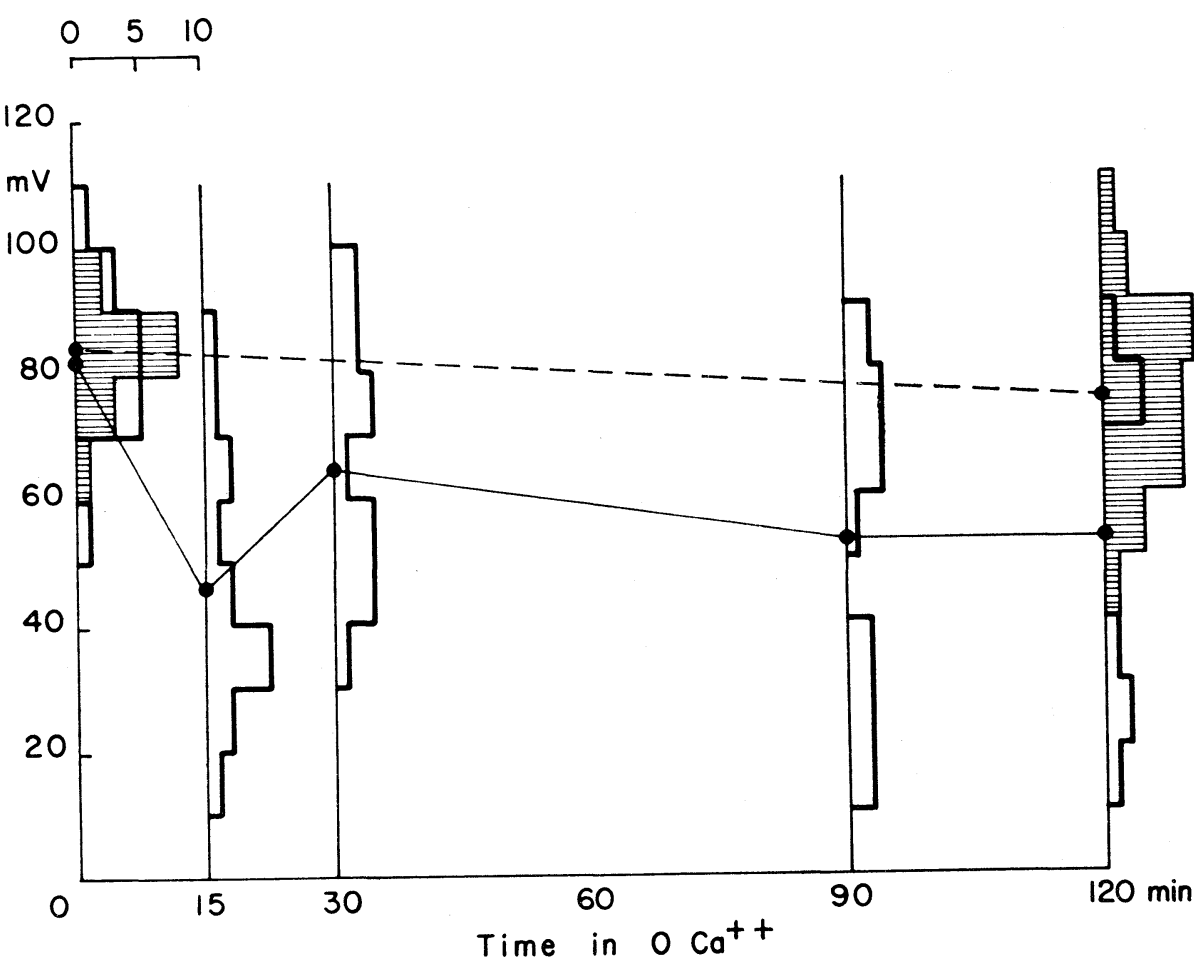

Fig. 6. Resting potentials of fibers in frog's toe muscles kept in a calcium-free Ringer solution. Details same as in Fig. 5 with exception that a different time sequence used for the grouping of potentials. 
level declined when the muscles were exposed to a calcium-free solution, the most striking effect was a change in the frequency distribution of the resting potentials. When measured in the control solutions $(0$ time) the resting potentials tended to be closely grouped about the mean $(82-84 \mathrm{mV})$ in a bell-shaped distribution (or occasionally a poisson distribution). When measured in a calciumfree solution the resting potentials tended to be randomly scattered over a wide range of potentials.

The reductions in the mean resting potential recorded for the first time after 1 or $2 \mathrm{hr}$ in a calcium-free solution (Figs. 5, 6, Table 3) were about the same magnitude as the depolarizations recorded using the sucrose-gap (see above). Only when the resting potentials were recorded several times during and after $1 \mathrm{hr}$ of exposure to the calcium-free solution were large mean depolarizations obtained. It is also of interest to note that the mean depolarization recorded after a 15 -min exposure to a 0 -calcium solution was usually larger than the mean depolarization measured from the other muscle of the pair after a 1- or 2-hr exposure to the calcium-free solution.

In contrast to the case in myelinated nerve fibers (FRANKENHAEUSER, 1957), action potentials could be produced in at least some muscle fibers exposed to a 0 -calcium Ringer solution for 1 or $2 \mathrm{hr}$ (Fig. 7). A similar observation was reported by IsHIKo and SATO (1957). However, excitability changes were not investigated in any detail and it is still possible that there are some inexcitable fibers with large resting potentials after exposure to a calcium-free solution or that the threshold was increased by this treatment (Frank, 1960; CAPUTO and GiMENEZ, 1967).
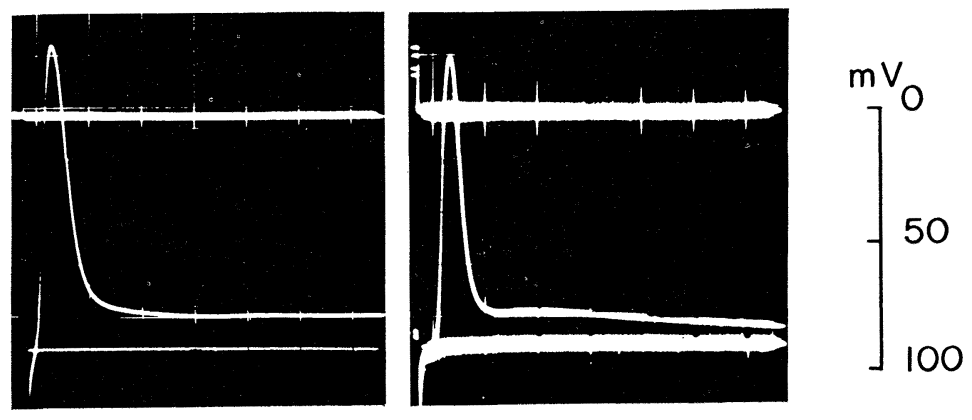

\section{$30 \mathrm{msec}$}

Fig. 7. Intracelluarly recorded action potentials from a fiber in Ringer solution (on left) and from a different fiber from the same muscle after a 2-hr exposure to a calcium-free Ringer solution. 


\section{DISCUSSION}

Although there is no doubt that the resting membrane potentials of frog skeletal muscle fibers are reduced when they are exposed to a calcium-free solution, as already mentioned above in the Introduction, there is a considerable discrepancy in the literature concerning the amount of this depolarization and the rate at which it develops. The results may be divided roughly into those reports showing a mean depolarization of about $15 \mathrm{mV}$ and those showing depolarizations $>20 \mathrm{mV}$. The rate at which this depolarization develops also varied in different reports. Thus LÜTTGAU (1963) observed an immediate fall in resting potential of about $10 \mathrm{mV}$ followed by a slower decline reaching a total depolarization of about $25 \mathrm{mV}$ in 15 to $20 \mathrm{~min}$, EDMAN and GRIEVE (1964) reported about a 25-mV depolarization after a 1-hr exposure to $0-\mathrm{Ca}^{++}$, and CURTIS (1963) using choline-Ringer, reported approximately a $60-\mathrm{mV}$ depolarization after a 25-min exposure to $0-\mathrm{Ca}^{++}$. In contrast, BRECHT et al. (1963) observed only a 10- to $15-\mathrm{mV}$ depolarization after an exposure to a $0-\mathrm{Ca}^{++}$solution for more than $3 \mathrm{hr}$.

The results obtained in the present study make it clear that exposing a frog's skeletal muscle to a calcium-free solution results in a slowly developing depolarization reaching a maximum of about $15 \mathrm{mV}$. This result was obtained either with the sucrose gap apparatus or with intracellular microelectrodes, provided the microelectrodes were first inserted into the fibers after the muscles had been exposed to a $0-\mathrm{Ca}^{++}$solution for $1 \mathrm{hr}$.

The first question which naturally arises from this conclusion, is what is the cause of the large depolarizations $(>20 \mathrm{mV})$ frequently reported? The answer would appear to be that it is an artifact produced by the insertion of intracellular microelectrodes into muscle membranes exposed to calcium-free solutions. We had no difficulty in obtaining large depolarizations provided we started recording with the microelectrodes 15 min after placing the muscle in the calcium-free solution. Although not investigated in detail, there was a tendency for the mean depolarization to increase with the frequency of microelectrode insertion.

If the change in the mean resting potential were due to a physiological change such as a change in membrane permeability or ion distribution, we would expect that in a calcium-free solution the mean resting potential would decline but that the frequency distribution of resting potentials about the mean would be about the same as in the presence of calcium. However, this is not the case (Figs. 5, 6). There is rather a random distribution of resting potentials in fibers from muscles exposed to 0-Ca $\mathrm{Ca}^{++}$solutions (EDMAN and Grieve, 1964; JENDEN and REger, 1963) or reduced $\mathrm{Ca}^{++}$solutions (BüLBRING et al., 1956). If the large depolarizations were an artifact produced by inserting microelectrodes into fiber membranes whose mechanical properties were changed by exposure to a $0-\mathrm{Ca}^{++}$solution, this might well explain this random distribution of resting potentials; i.e., the amount of depolarization varying with the damage produced at the instant of 
insertion or residual depolarization remaining from a previous insertion. An artifact of this type also would help to explain the great variability in the reports from different laboratories concerning the extent and the development rate of this depolarization.

Although it has been proposed that the membrane depolarization produced in excitable cells by exposure to calcium-free solutions is due to an increase in the relative $\mathrm{Na}^{+}$permeability of the membrane (KOKETSU, 1969), this would appear not to be the cause of the small depolarization (about $15 \mathrm{mV}$ ) found in the present study. The main basis for this conclusion is that the depolarization is not prevented by the replacement of $\mathrm{Na}^{+}$ions by choline ions in the calcium-free solution. Thus the most likely explanation would seem to be that the removal of extracellular calcium ions (and presumably calcium superficially bound to the membrane) causes a generalized or nonspecific increase in membrane permeability resulting in the uptake of $\mathrm{Na}^{+}$ions (or choline ions) by the muscle fibers and a consequent loss of intracellular $\mathrm{K}^{+}$ions. This process continues until a new equilibrium level (or resting potential) is established. A mechanism of this type would be in keeping with the observations that the rate at which the depolarization develops is slow and takes many min to reach a steady level after the removal of calcium ions, that it takes even longer ( 2 to 3 times) for the control resting potential to be restored after replacing calcium in the bathing solution, and that small concentrations of calcium $(0.05-0.10 \mathrm{~mm})$ are sufficient to completely prevent the depolarization.

We wish to thank Mr. Richard S. Neuman who designed the electrodes for the sucrose gap apparatus and developed the procedure for purifying the sucrose.

\section{REFERENCES}

Aвood, L. G., Koyama, I., and Kimizuka, H. (1963) A possible mechanism of action of calcium and some psychotomimetic agents on membranes. Nature (Lond.), 197: 367-368.

Brecht, K., Kutscha, W., and Pauschinger, P. (1963) Kontraktur, zuckung und calcium. Pflügers Arch. Ges. Physiol., 277: 178-193.

Bülbring, E., Holman, M. and LÜllmanN, H. (1956) Effects of calcium deficiency on striated muscle of the frog. J. Physiol., 133: 101-117.

Caputo, C. and Gimenez, M. (1967) Effects of external calcium deprivation on single muscle fibers. J. Gen. Physiol., 50: 2177-2195.

Curtis, B. A. (1963) Some effects of Ca-free choline-Ringer solution on frog skeletal muscle. J. Physiol., 166: 75-86.

Edman, K. A. P. and Grieve, D. W. (1962) The role of calcium and zinc in the electrical and mechanical responses of frog sartorius muscle. Experientia, 17: 557-558.

Edman, K. A. P. and Grieve, D. W. (1963a) The decremental propagation of the action potential and loss of mechanical response in frog sartorius muscle in the absence of calcium. Experientia, 19: 40.

Edman, K. A. P. and Grieve, D. W. (1963b) A calcium dependent link beyond the electrical excitation of the membrane in muscular contraction. Experientia, 19: 40-41.

Edman, K. A. P. and Grieve, D. W. (1964) On the role of calcium in the excitation-contraction process of frog sartorius muscle. J. Physiol., 170: 138-152. 
Fischman, D. A. and SwAN, R. C. (1967) Nickel substitution for calcium in excitation-contraction coupling of skeletal muscle. J. Gen. Physiol., 50: 1709-1728.

FrANK, G. B. (1960) Effects of changes in extracellular calcium concentration on the potassiuminduced contracture of frog's skeletal muscle. J. Physiol., 151: 518-538.

FrANK, G. B. (1964) Evidence for an essential role for calcium in excitation-contraction coupling in skeletal muscle. Proc. R. Soc. B., 160: 504-512.

Frank, G. B. and Inoue, F. (1972) Membrane potential of frog's skeletal muscle in $\mathrm{Ca}^{++}$-free solutions. Fifth International Congress on Pharmacology, Abstracts of Volunteer Papers, 71.

Frankenhaeuser, B. (1957) The effect of calcium on the myelinated nerve fibre. $J$. Physiol., 137: 245-260.

Frankenhaeuser, B. and Hodgkin, A. L. (1957) The action of calcium on the electrical properties of squid axons. J. Physiol., 137: 218-244.

GAINER, H. (1968) The role of calcium in excitation-contraction coupling of lobster muscle. J. Gen. Physiol., 52: 88-110.

Inoue, F. and Frank, G. B. (1962) Action of procaine on frog skeletal muscle. J. Pharmacol. Exp. Ther., 136: 190-196.

Ishixo, N. and SATo, M. (1957) The effect of calcium ions on electrical properties of striated muscle fibres. Jap. J. Physiol., 7: 51-63.

JENDEN, D. J. and Reger, J. F. (1963) The role of resting potential changes in the contractile failure of frog sartorius muscles during calcium deprivation. J. Physiol., 169: 889-901.

Koketsu, K. (1969) Calcium and the excitable cell membrane. In Neurosciences Research, ed. by Ehrenpreis, S. and Solnitzky, O. C. Academic Press, New York, Vol. 2.

KoKetsu, K. and NodA, K. (1962) Membrane responses of frog skeletal muscle fibers in calcium-free media. J. Cell. Comp. Physiol., 59: 323-332.

LÜTTGAU, H. C. (1963) The action of calcium ions on potassium contractures of single muscle fibres. J. Physiol., 168: 679-697.

Milligan, J. V. (1965) The time course of the loss and recovery of contracture ability in frog striated muscle following exposure to Ca-free solutions. J. Gen. Physiol., 48: 841-858.

STÄMPfli, R. (1954) A new method for measuring membrane potentials with external electrodes. Experientia, 10: 508.

STÄMPFLI, R. and NiSHIE, K. (1956) Effects of calcium-free solutions on membrane-potential of myleinated nerve fibers of the Brazilian frog Leptodacylus ocellatus. Helv. Physiol. Pharmacol. Acta, 14: 93-104.

ZACHAROVÁ, D. and ZACHAR, J. (1967) The effect of external calcium ions on the excitationcontraction coupling in single muscle fibres of the crayfish. Physiol. Bohemoslov., 16: 191207. 